\title{
A GESTÃO MUNICIPAL DA VIOLÊNCIA COMO UMA QUESTÃO DE GOVERNAMENTALIDADE
}

\author{
Letícia Fonseca Paiva Delgado*
}

\section{REsUMO}

A partir de novos formatos organizacionais que colocam em termos estratégicos a importância da inserção do município nas discussões sobre segurança pública no contexto brasileiro pós-constituição de 1988, o presente artigo tem por finalidade principal traçar a relação entre o processo de inclusão do município como ente central na implementação de políticas de segurança pública e o conceito Foucaultiano de governamentalidade. A ferramenta metodológica - apresentada pelo autor durante suas aulas no Collège de France - busca compreender um saber político que tem como preocupação central as noções de população e dos mecanismos capazes de assegurar sua regulação. A percepção da gestão da criminalidade enquanto umas das situações das quais o governo deve se encarregar permitirá a identificação de uma nova racionalidade frente às formas tradicionais de pensar a segurança pública, que se relaciona diretamente com o discurso e estratégias que reforçam a importância da participação do poder local no gerenciamento da criminalidade.

Palavras-chave: Segurança Pública; Município; Governamentalidade; Michael Foucault.

\section{CITY VIOLENCE MANAGEMENT AS A GOVERNMENTALITY ISSUE}

\section{ABSTRACT}

According to new organizational formats that put in strategic terms the importance of city's insertion in discussions about public safety in Brazilian post-constitution context, this article intends to draw the relationship between city's inclusion process as central entity in the implementation of public safety policies and Foucauldian concept of governmentality. The methodological tool - introduced by the author during his classes in Collège de France - seeks to understand the political knowledge which has as its main concerns the notions of population and its mechanisms of regulation. The perception of crime management as a situation of which the government must take responsibility of will allow identification of a new rationality regarding traditional forms of thinking public safety - which is directly related to the speech and the strategies that reinforce the importance of local power participation in crime management.

Key-words: Public Safety, City, Governmentality, Michael Foucault.

\section{LA GESTIÓN MUNICIPAL DE LA VIOLENCIA URBANA COMO UNA CUESTIÓN DE GUBERNAMENTALIDAD}

\section{RESUMEN}

Partiendo de nuevos formatos de organización que ponen en términos estratégicos la importancia de la inclusión de la ciudad en las discusiones acerca de la seguridad pública en el contexto brasileño posterior a la Constitución de 1988, este artículo se pretende, principalmente, a diseñar la relación entre el proceso de inclusión del municipio como pieza central en la implementación de políticas de seguridad pública y el concepto foucaultiano de la gubernamentalidad. A herramienta metodológica - presentado por el autor durante sus conferencias en el Collège de France - trata de comprender un saber político que pone en el centro de sus preocupaciones la noción de población y de los mecanismos capazes de asegurar su regulación. La percepción de la gestión de la delincuencia como una de las situaciones de las cuales el gobierno debe encargarse permite la identificación de una nueva racionalidad diante de las formas tradicionales de pensar en la seguridad pública, que está directamente relacionada con el discurso y las estrategias que refuerzan la importancia de la participación del poder en la gestión de la criminalidad.

Palabras-Clave: Seguridad Pública; Municipios; Gubernamentalidad; Michael Foucault.

* Bacharel em Direito - UFJF, Doutoranda do PPGSD/UUF e professora do Curso de Direito da Doctum-JF. Contato: lfpdelagado@hotmail.com 
INTRODUÇÃO

Creio que é preciso ter a modéstia de dizer que, por um lado, o momento em que vivemos não é esse momento único, fundamental ou irruptivo da história a partir do qual tudo termina e tudo recomeça; é preciso ter a modéstia de dizer, ao mesmo tempo, que mesmo sem esta solenidade - o momento em que vivemos é muito interessante, e precisa ser analisado, decomposto e que, com isso, temos que nos colocar a questão: o que é o hoje? (Michel Foucault)

As questões correlatas ao aumento da violência urbana, principalmente após a década de 1990, trouxeram consequências nos aspectos simbólico, econômico e político. A noção de que a insegurança urbana produz efeitos no plano político é apresentada por especialistas que afirmam que "os problemas ligados à área da segurança pública são politizados à medida que a legitimidade dos governos é predominantemente determinada por sua capacidade de manter a ordem e uma possível paz social" (BARREIRA, 2004, p. 77). Neste contexto, a segurança pública entra para agenda municipal. É a construção de um novo formato organizacional e institucional que destina ao município - enquanto ente federado - um papel central na gestão da violência urbana.

Ainda incipiente, $\mathrm{o}$ debate se insere dentro de uma nova perspectiva de governança que reforça a participação do poder local como um dos elementos de constituição de um modelo de segurança pública cujo foco é o cidadão. A compreensão deste processo nos levou ao encontro de um novo paradigma: a Segurança Pública Cidadã -, que se estrutura, dentre outros, pela percepção de ser o município um local privilegiado de exercício da cidadania. No plano legal-normativo, uma nova concepção de segurança pública é percebida através do reconhecimento formal pelo Programa Nacional de Segurança Pública com Cidadania - Pronasci criado através da Lei 11530/2007, da necessidade de um novo "olhar" para estas políticas públicas. As normas jurídicas são um tipo de poder capaz de produzir discursos de verdade, que são fundamentais para o próprio exercício do poder.
Assim, a percepção do ordenamento jurídico é uma das formas que nos permite assimilar os mecanismos de poder. (FOUCAULT, 2005, p.28).

A busca pelo conhecimento das condições históricas em que os discursos oficiais sobre segurança pública no Brasil se estruturaram, a clamar, inclusive, pela inserção do município no debate, será orientada pela preocupação critica de entender o presente. Neste ponto, ladeando a metodologia utilizada por Garland (2008) para explicar como as respostas criminológicas assumiram suas características atuais, o "objetivo não é pensar historicamente o passado, mas sim, através da história, repensar o presente" (GARLAND, 2008, p. 43). A existência de distintos paradigmas que determinaram as formulações de políticas públicas de segurança no Brasil é sinalizada por Freire (2009) que, de acordo com os objetivos e estratégias, apresenta os modelos identificados como Segurança Nacional, Segurança Pública e Segurança Cidadã, a partir de um recorte temporal das últimas cinco décadas. A compreensão das formulações - por refletirem ou serem o reflexo da atuação estatal e da percepção da sociedade sobre o tema em determinado contexto histórico, político e social - é essencial para a identificação dos continuísmos, rupturas, estratégias e racionalidades que permearam a formulação das políticas públicas. Segundo Fraga (2002, p.70), "a noção de governamentalidade se efetiva como ferramenta de investigação de poder, forjada por percursos de continuidades e rupturas de seu pensamento".

A abordagem pretendida nos permitirá investigar qual o tipo de racionalidade que norteia a relação entre segurança pública e a municipalidade. Por racionalidade, compreendemos aquilo que "programa e orienta o conjunto da conduta humana. Há uma lógica tanto nas instituições quanto na conduta dos indivíduos e nas relações políticas". (FOUCAULT, 2003, p. 319). A racionalidade do Estado e a arte de governar os homens se relacionam, sendo a política a maneira de pensar, raciocinar e calcular as artes de governar. Analisar o tipo de racionalidade implicada no exercício de poder do Estado - de sua organização política, de seus mecanismos de sustentação e organização, de seus saberes e da arte de governar - é uma das tarefas necessárias para a análise do próprio Estado. 
Podemos fazer a genealogia do Estado moderno e dos seus diferentes aparelhos a partir de uma razão governamental. Sociedade, economia e população, segurança e liberdade: são os elementos da nova governamentalidade, cujas formas, parece-me, ainda conheceremos em suas modificações contemporâneas. (FOUCAULT, 2008, p. 476).

O Estado aparece articulado nas atividades de governo, sendo indispensável a identificação do "como" de sua atuação através das análises de suas políticas públicas, técnicas governamentais, programas, ou melhor, estratégias para a manutenção das condições de governo. Neste sentido, Miller e Rose (2008, p.76), afirmam que o Estado deveria, antes de tudo, ser compreendido como uma resultante complexa e móvel dos discursos e técnicas de governo.

Afirmamos, porém, que as problemáticas do governo deveriam também ser analisadas em termos de suas tecnologias governamentais, do complexo de programas rotineiros, cálculos, técnicas, aparatos, documentos e procedimentos mediante os quais as autoridades buscam incorporar e por em prática ambições governamentais. (MILLER, ROSE, 2008, p. 72).

Shore e Write (1997), afirmam que uma das formas de compreensão do Estado é através das políticas públicas. Assim, a identificação das estratégias, racionalidades, em suma, a apreensão das políticas de segurança pública através do que Foucault (2013, p. 366) denomina de "preenchimento estratégico do dispositivo", será o método elegido para a construção da relação entre o processo de inserção do município como promotor de politicas de segurança pública e a ideia de governamentalidade.

O objetivo principal deste artigo é perceber a relação entre o processo de inclusão do município nos debates sobre a gestão das políticas de segurança pública no contexto brasileiro pós-constituição de 1988 e o conceito Foucaultiano de governamentalidade. Delineada a finalidade principal deste trabalho, mapearemos quais os paradigmas de segurança pública identificados durante a história, bem como a relação de tais modelos com o processo de protagonismo do poder público municipal nessa área de atuação. Posteriormente, a fim viabilizar teoricamente a discussão central, analisaremos o conceito de governamentalidade, enquanto ferramenta metodológica que, relacionada à problemática do Estado Moderno, situa-se na gênese de uma saber político que coloca no centro de suas preocupações a noção de população e dos mecanismos capazes de assegurar sua regulação. Por fim, buscaremos perceber como a construção de uma nova racionalidade frente às formas tradicionais de segurança pública - racionalidade esta que estimula a participação do município no gerenciamento da criminalidade - é resultado de uma nova estratégia que se relaciona diretamente com a questão de como governar, como ser governado, como fazer para ser o melhor governante possível.

O artigo, essencialmente teórico, será estruturado em duas partes. A primeira será destinada à apresentação, ainda que superficial, dos paradigmas de segurança pública percebidos historicamente no Brasil, a fim de identificar novos formatos organizacionais e discursivos que permitem e fomentam a participação do Município na gestão da violência urbana. $\mathrm{O}$ segundo buscará a compreensão do conceito de governamentalidade, apresentado por Michael Foucault durante suas aulas no Collège de France, bem como a relação desta ferramenta metodológica com a discussão principal que orienta o presente estudo.

\section{O MUNICÍPIO E A SEGURANÇA PÚBLICA: PARA COMPREENDER O PRESENTE, UM RETORNO AO PASSADO.}

O objetivo não é pensar historicamente o passado, mas sim, através da história, repensar o presente. (Garland, 2008)

No Brasil, principalmente nas décadas de 1980 e 1990, as discussões sobre o aumento da criminalidade se acentuaram. Segundo a Organização Panamericana de Saúde (Paho), o Brasil, entre 1996 a 1999, atribuiu 35,6\% das suas mortes externas a homicídios, percentagem bem 
significativa em comparação aos outros países do continente Americano pesquisados. Em relação à vitimização juvenil, de acordo com a mesma pesquisa, o Brasil ocupou o primeiro lugar em mortes por homicídios de jovens entre 15 a 24 anos. Segundo o Mapa da Violência de 2013, em um período de 30 (trinta) anos, observamos um aumento percentual de $414 \%$ de óbitos em virtude de agressões por arma de fogo entre os jovens de 15 a 29 anos no Brasil. Dentro desta faixa, em 1980 o SIM - Subsistema de Informação sobre Mortalidade - contabilizou 4.415 óbitos, contra 22.694 em 2010 (WAISELFISZ, 2013). Com a taxa de 27,4 homicídios por 100 mil habitantes, comparativamente, o país ocupa a sétima posição no conjunto dos 95 países mais violentos do mundo, segundo dados fornecidos pela OMS e analisados nos períodos compreendidos entre 2007 e 2011. (WAISELFISZ, 2014). Os dados comparativos do perfil da violência no Brasil apontam para uma característica importante: os processos de disseminação e interiorização teriam causado o deslocamento da violência de municípios de grande porte - acima de $100 \mathrm{mil}$ habitantes - para municípios de pequeno e médio porte. Apesar dos números apresentados serem relacionados a homicídios, os dados demonstram - não somente um crescimento - como uma alteração da dinâmica da criminalidade. Esses deslocamentos, responsáveis por uma nova geografia do crime, produzem consequências nos planos simbólico, econômico e político, tornando-se uma das principais preocupações das populações urbanas brasileiras.

No plano político, o aumento da criminalidade demanda do poder público novas formas de pensar a segurança pública, focadas em estratégias capazes de manter a confiança da população nas instituições. Segundo Soares (2005, p.28), "Os eleitores não querem mais saber se o problema é federal, estadual ou municipal. Querem soluções. Desejam optar entre propostas viáveis, práticas e urgentes". Tal análise se alinha com a percepção de Barreira (2004, p. 77), para quem "os problemas ligados à área da segurança pública são politizados à medida que a legitimidade dos governos é predominantemente determinada por sua capacidade de manter a ordem e uma possível paz pública”.

Em consequência, novos formatos organizacionais e institucionais surgem imbuídos de uma nova concepção de segurança pública. $\mathrm{O}$ discurso de ampliação do papel do município na área de segurança pública se fortalece e é potencializado pelo agravamento do quadro e ao desconforto da sociedade com a tradição do imobilismo municipal. Em um contexto em que as delimitações constitucionais e o discurso da ausência de responsabilidade deixam de satisfazer o eleitorado, a segurança pública entra na agenda municipal.

A busca, entretanto, pela compreensão da inserção da temática segurança pública na agenda municipal perpassa pelo conhecimento das condições históricas que ensejaram a construção dos diversos paradigmas de segurança pública ao longo da história brasileira. Ladeando a metodologia utilizada por Garland (2008) para explicar como as respostas criminológicas assumiram as feições contemporâneas, a orientação histórica estará direcionada mais por uma preocupação crítica de entender o presente do que por uma preocupação histórica de entender o passado.

Freire (2009) sinaliza que a melhor compreensão da dinâmica atual da violência e as alternativas públicas disponíveis para seu enfrentamento perpassam pela reflexão sobre o histórico das políticas de segurança no país. As diversas formas de atuação e configuração percebidas em determinado local e períodos se relacionam diretamente aos conceitos $\mathrm{e}$ paradigmas que atuam como base para a formulação das políticas públicas de segurança. Segundo a autora, a existência de visões de mundo compartilhadas, em determinados períodos, influenciam a forma de pensar de determinado grupo e, consequentemente, a produção científica e a formulação de políticas públicas. A identificação destes paradigmas é importante "para melhor conhecer os objetivos dos formuladores de políticas e os resultados que estas podem trazer para a sociedade". (FREIRE, 2009, p. 49). Indicando como marco temporal o último período ditatorial vivenciado no Brasil, Freire (2009) apresenta três paradigmas de Segurança Pública, identificáveis como Segurança Nacional, Segurança Pública e Segurança Cidadã. O paradigma de "Segurança Nacional" relaciona-se diretamente à existência do período de Ditadura Militar percebido no Brasil de 1964 a 1985. Dentro desta perspectiva, as ações da área da segurança eram direcionadas para as defesas do Estado, da ordem política e social. A supre- 
macia inquestionável do interesse nacional - ditado por uma elite no poder - era, segundo Freire (2009), a lógica que fundamentava o uso da força para a preservação da ordem. Em um contexto de supressão de direitos e garantias individuais, as Forças Armadas emergem como intérpretes da vontade nacional.

O rótulo de "inimigo interno" é um fator importante para o fortalecimento do regime e se torna essencial para o recrudescimento das estratégias bélicas de controle social. Cria-se um novo criminoso, o revolucionário, que demanda pesados investimentos direcionados à formulação de uma "nova polícia" capaz de imobilizá-lo. Esta estratégia de gerenciamento de criminalidade, além de satisfazer os anseios de um determinado momento político, justifica políticas de segurança fortemente centralizadas e alinhadas com um discurso repressivo. Orientada por essa racionalidade e fortemente influenciada pelo protagonismo das Forças Armadas, as políticas de segurança pública deste momento histórico convergem com o conceito de Segurança Nacional trazido por Freire (2009, p.51), definido "como a habilidade de um Estado em garantir, em determinada época, a obtenção e manutenção de seus objetivos nacionais, apesar dos antagonismos ou pressões existentes ou potenciais".

Conceitualmente, o paradigma "Segurança Nacional" foi superado por uma nova ordem constitucional que se dizia mais apta a assegurar e proteger os direitos e garantias individuais. A Constituição Federal de 1988 rompe formalmente como o regime autoritário até então vigente e, ao menos retoricamente, reconhece no cidadão a centralidade das preocupações do Estado. É um diploma normativo que - fortemente influenciado pelo discurso da universalização dos direitos humanos pós Segunda Guerra Mundial - passou a influenciar políticas governamentais no Brasil, após a década de 1990 (MESQUITA, 2009). Apesar do marco histórico-legal, recorrentes são os estudos que apontam para uma superação apenas "formal" do paradigma anterior, fato este que estaria relacionado à manutenção das estruturas autoritárias das instituições policiais, atores centrais na concepção de Segurança Pública. Neste sentido, Choukr (2004) e Zaverrucha (2008), apud Kruchin (2013).

Em relação à formação da Polícia Militar, uma breve exegese nos aponta para o Decre-
to-Lei $n^{\circ}$ 667, de 02 de julho de 1969, que evidencia a inexistência de solução de continuidade entre as Forças Armadas e as instituições destinadas à realização da Segurança Pública. Apesar de a Constituição Federal de 1988 ter marcado a institucionalização do processo de transição para a democracia, em que os órgãos responsáveis pela manutenção da ordem pública passam a ter a necessidade de atuação em consonância com princípios democráticos, Carvalho e Silva (2011) afirmam que os resquícios do período ditatorial permanecem encravados nas práticas policiais e, desta forma, podem ser obstáculos para a institucionalização de um novo arcabouço organizacional e administrativo dos órgãos incumbidos da segurança no país. $\mathrm{O}$ autoritarismo e o centralismo das instituições policiais são recorrentemente citados como obstáculos à efetivação de um novo paradigma de Segurança Pública.

No entanto, não há como deixar de reconhecer a mudança que a nova ordem normativa constitucional trouxe para o campo da segurança, a permitir, inclusive, a percepção de um novo paradigma a orientar as ações praticadas. Uma importante inovação da Constituição Federal de 1988 foi promover a separação entre as funções de polícia (art. 144 da CF) e funções das Forças Armadas (art. 142 da CF). Segundo Freire (2009, p. 51), "essa separação de papéis transcrita no texto da Constituição é importante, pois destaca a distinção entre Segurança Pública e Segurança Nacional: a primeira é voltada à manifestação da violência no âmbito interno do país e, a segunda, refere-se a ameaças externas à soberania nacional e defesa do território".

Através dos pontos apresentados, percebe-se que um dos aspectos principais dentro do paradigma de Segurança Pública é o deslocamento do controle do crime das forças armadas para as instituições policiais, bem como uma divisão rígida de competências no plano federativo, conferindo aos estados-membros grande autonomia para a concepção e execução de suas próprias políticas no setor (Silva, 2011). No entanto, apesar de mencionar que a segurança pública é direito e responsabilidade de todos, a Constituição Federal confere uma centralidade de atuação aos órgãos policiais, deixando de explicitar o papel das demais instituições e/ou instâncias envolvidas. Assim, não há clareza no texto legal sobre a importância e/ou forma da atuação dos municípios. Silva (2011) afirma que o panorama das políticas 
de segurança pública, até o início dos anos 2000, foi marcado pela ação limitada do governo federal - baseada na mobilização da Polícia Federal e Polícia Rodoviária Federal -, e na centralidade das ações ostensivas na Polícia Militar, agenda esta pertencente aos governos estaduais.

É possível perceber, portanto, uma mudança do foco na ação das políticas de segurança pública quando comparamos os dois paradigmas: "Segurança Nacional” e "Segurança Pública”. Enquanto no primeiro as ações eram voltadas para a manutenção da ordem pública, através da inocuização de condutas que representassem ameaças contra os interesses nacionais, no arcabouço da segurança pública as ações - que também visam à manutenção da ordem pública - se dirigem contra condutas tendentes a ameaçar a integridade das pessoas e o patrimônio. Assim, através das políticas de segurança, o governo passa a gerir questões diversas da população, ultrapassando-se a lógica da mera preservação do território.

Apesar da clara alteração paradigmática observada após promulgação da $\mathrm{CF} / 88$, as reinvindicações para a implementação de um modelo que superasse concretamente o modelo repressivo do período político anterior aparecem com mais ênfase na última década (KRUNCUIN, 2013). O gradual processo de redemocratização da sociedade e, principalmente, a percepção da natureza multicausal da violência - a merecer diversas e criativas formas de atuação no campo das políticas públicas de segurança - evidenciam, no contexto brasileiro, o processo de construção da perspectiva que podemos denominar "Segurança Cidadã”, referencial para o reconhecimento da importância do engajamento Municipal nas discussões e ações na área da segurança.

Segundo Freire (2009), no Brasil, é possível perceber tentativas de aproximação deste conceito nos últimos anos. Um dos marcos apresentados é o Projeto de cooperação técnica "Segurança Cidadã", iniciado em 2003, fruto de uma parceria entre a Secretaria Nacional de Segurança Pública e as Nações Unidas, com a colaboração de técnicos colombianos. No entanto, desde 1995, com a criação em âmbito federal da Secretaria de Planejamento de Ações Nacionais de Segurança Pública - transformada em 1997 na Secretaria Nacional de Segurança Pública (Senasp) - e, principalmente, com a construção do I Plano Nacional de Segurança Pública (1994-2002) e a criação do Plano Nacional de Segurança Pública, percebemos uma tentativa de articular as ações de repressão e prevenção à criminalidade no País.

Durante o $1^{\circ}$ governo do então presidente Luiz Inácio Lula da Silva, algumas mudanças foram aprimoradas. A orientação era no bom diagnóstico da violência e da criminalidade como forma de alimentar as ações de prevenção orientadas e monitoradas por atores da segurança pública. A implementação do Sistema Único de Segurança Pública, por sua vez, surgiu como plataforma eleitoral para o programa de governo durante a disputa eleitoral de 2002. Inspirado no Sistema Único de Saúde, o SUSP pretende articular e integrar as ações dos três entes federados, a fim de aperfeiçoar o planejamento e trocas de informações para o êxito das ações na área. Apesar de não buscar a unificação, a lógica integrativa está estruturada em seis eixos: gestão unificada da informação; gestão do sistema de segurança; formação e aperfeiçoamento de policiais; valorização das perícias; prevenção e ouvidorias independentes e corregedorias unificadas. (FREIRE, 2009, p. 52).

Criado no ano de 2007, o Programa Nacional de Segurança Pública com Cidadania - PRONASCI - deslocou o equilíbrio de prioridades entre repressão e prevenção e valorizou a protagonismo dos municípios na elaboração e na execução do PNSP. Trata-se de uma tentativa de criação de uma política de Estado, capaz de proporcionar autonomia administrativa, financeira, orçamentária e funcional das instituições envolvidas, nos três níveis de governo. Neste paradigma, a descentralização alcança não somente os municípios, como também o cidadão, fator este que justifica a expressão Segurança Cidadã, como identificador de um novo paradigma, olhar, para as políticas de segurança pública. Segundo Freire (2009, p. 59), na Segurança Cidadã a participação social pode ser vista como uma mudança cultural, pois o é individuo é o centro da política e seu principal beneficiário.

O processo de consolidação de um paradigma de segurança cidadã no Brasil ainda é um fenômeno em construção. Tal concepção, entretanto, parte da premissa de que a prevenção, $o$ controle, a sanção e a repressão da violência e da delinquência são responsabilidade dos entes estatais, sem detrimento, entretanto, das responsabilidades que cabem à sociedade civil. O Programa das Nações Unidas para o Desenvolvimento - PNUD -, apresenta a definição de política de 
segurança cidadã

como o conjunto de intervenções públicas realizadas por diferentes atores estatais e sociais voltados para a abordagem e a resolução daqueles riscos e conflitos (concretos ou previsíveis) violentos e/ou delituosos que lesem os direitos e as liberdades das pessoas, mediante a prevenção, o controle e/ou a repressão dos mesmos. Uma política eficaz deve ser o resultado de uma análise detalhada da situação, considerar metas de médio e longo prazo se compreender ferramentas ou instrumentos que englobem os diversos tipos de problemas que terá que enfrentar para prevenir e reduzir os fenômenos de violência e delinquência. (PNUD, 2007, p.10-11).

Percebe-se que na perspectiva apresentada, o foco de atuação das políticas de segurança pública é o cidadão. Assim, permanece a proteção à vida e à propriedade, como delineia o paradigma de segurança pública, porém a proteção avança rumo à plena cidadania, sendo a violência percebida como um dos fatores que inviabilizam sua efetivação. As políticas preventivas, bem como as integradas - capazes de mobilizar a participação social e os diversos entes federativos - ganham importância. É neste arcabouço conceitual e paradigmático que o município passa a ser reconhecido como um dos entes centrais na implementação e na gestão das políticas de segurança pública.

No plano político-administrativo, a possibilidade de atuação do Município na área da segurança pública reflete uma tendência à descentralização. A inteligência de ser o Brasil um país de grandes dimensões colide com a visão centralizadora e conforma o argumento de que políticas públicas formuladas em termos gerais e homogeneizantes não seriam eficientes ante às diversidades territorial, cultural $\mathrm{e}$ social brasileiras. O princípio da proximidade, entendido como a possibilidade de estabelecer uma relação direta e imediata da organização representativa e da estrutura administrativa com o território e a população (CASTELLS e BORJA, 1996), passa a ser o elemento legitimador da autonomia e elemento essencial da legitimação democrática. Castells e Borja (1996) reconhecem que a democratização e a descentralização dos
Estados reforçaram e deram maior legitimidade aos governos locais, posto que a cidade apresenta-se como espaço de debate público e de articulação entre os atores urbanos. A capacidade de o município de envolver a população com o planejamento local das ações de segurança é recorrente na literatura. $\mathrm{O}$ debate pode ser inserido na busca por legitimação social das ações políticas: pelo princípio da proximidade, os municípios estariam mais aptos a "chamarem" os cidadãos à tomada de decisões, aderência esta importante para a maior legitimação das medidas "impopulares".

Sendo a cidade o "locus" de vivência dos problemas relacionados à criminalidade, o município passa a ser percebido como um espaço legítimo de definição de estratégias nesta área de atuação. A ação dos gestores públicos locais, notadamente em relação ao seu poder de articulação com as diferentes instituições, atores sociais, comunidade, bem como proximidade com o espaço geográfico e social em que ocorrem os crimes é ressaltada. Capacidade de articulação, soluções locais e proximidade entre comunidade e prefeitura são apresentadas como as grandes marcas da administração municipal, consideradas como fatores fundamentais para a formulação de políticas públicas de segurança e ações eficazes de combate à violência (MIRAGLIA, 2008; RICCIO, 2012). O território, o espaço local, ressurge como lugar estratégico para as políticas públicas, "abrindo espaço para a introdução de novos conceitos e novas práticas de gestão caracterizadas por maior participação dos beneficiários, mais flexibilidade na operacionalização das intervenções, valorização do território como unidade da ação e integração das redes locais" (ALVES, s.d., p.66).

Os argumentos que buscam justificar as mudanças paradigmáticas na concepção das políticas de segurança pública e, consequentemente, a reconfiguração do campo do controle do crime que, nos dizeres de Garland (2008, p. 48), "é o resultado de escolhas políticas e de decisão administrativas ambas assentadas sobre uma nova estrutura das relações sociais e informadas por um novo padrão de sensibilidade cultural", podem ser percebidos como ações estratégicas que, ao buscarem impactar sobre a criminalidade e consequentemente sobre a população, visam fortalecer o próprio poder do Estado. Neste campo, estamos diante de um 
discurso fortemente baseado na descentralização das politicas de segurança pública; no reconhecimento das potencialidades do poder local em ações preventivas à criminalidade; das cidades como atores políticos, promotoras de cidadania e capazes de efetivar mecanismos de participação sociais mais desenvolvidos. Uma nova racionalidade na construção dos discursos oficiais sobre segurança pública no Brasil que orienta novas formas de governar.

Por racionalidade, a partir do sentido conferido por Foucault, compreendemos aquilo que "programa e orienta o conjunto da conduta humana. Há uma lógica tanto nas instituições quanto na conduta dos indivíduos e nas relações políticas". (FOUCAULT, 2003, p. 319). A racionalidade do Estado e a arte de governar os homens se relacionam, sendo a política a maneira de pensar, raciocinar e calcular as artes de governar. Analisar o tipo de racionalidade implicada no exercício de poder do Estado - de sua organização política, de seus mecanismos de sustentação e organização, de seus saberes e da arte de governar - é uma das tarefas necessárias para a análise do próprio Estado.

\section{A GOVERNAMENTALIZAÇÃO DO ESTADO E A GESTÃO MUNICIPAL DA SEGURANÇA PÚBLICA: UMA RELAÇÃO POSSÍVEL.}

De acordo com Foucault (2013), a governamentalização, percebida desde o século XVIII, foi o fenômeno que permitiu ao Estado sobreviver, a partir do momento em que os problemas de governamentalidade, as técnicas de governo, se tornaram a questão política fundamental e o espaço real da luta política. "São as táticas de governo que permitem definir a cada instante o que deve ou não competir ao Estado, o que é público ou privado, o que é ou não é estatal etc" (FOUCAULT, 2013, p. 430).

O questionamento sobre a maneira de se governar e de se conduzir acompanha o fim da ordem feudal e o nascimento de novas relações econômicas e sociais, e de novas estruturas políticas. Da chamada "crise geral do pastorado", durante os séculos XV e XVI, decorreu o deslocamento de uma tônica e o aparecimento de novos problemas, objetivos e técnicas. No entanto, tal deslocamento não pode ser entendido como uma ruptura com a lógica do poder pastoral, e sim com uma nova configuração, como uma nova forma de saber/poder, agora baseada no governo dos homens. (FOUCAULT, 2008). O poder pastoral, por se exercer sobre seres vivos e não sobre um território, como o poder soberano, se aproxima do biopoder. Trata-se, portanto, do governo dos vivos.

Fraga (2002), afirma que ao longo do século XVIII, observa-se uma biopolítica da espécie, uma vez que todos os elementos da população tornam-se objeto de saber, permitindo a tomada da vida pelo poder. Se a disciplina objetiva a tomada do poder pelo corpo, as tecnologias não disciplinares são massificantes, "governando-se os nascimentos, as mortes, a produção de doenças, a fecundidade de uma população" (FRAGA, 2002 , p. 87). O que se busca no biopoder é aumentar a vida, atuando preventivamente sobre condutas individuais e coletivas e levando-se em consideração elementos da população. A melhor forma de governar a população passa a ser a problemática fundamental do Estado moderno, que possui o papel fundamental de governar.

Através da passagem do poder pastoral ao biopoder, Foucault insere assim, em seus estudos, a questão do governo, ou a arte de governar: "como se governar, como ser governado, como fazer para ser o melhor governante possível". A problemática geral do governo, que aparece com intensidade particular no século XVI, é “o problema de como ser governado, por quem, até que ponto, com qual objetivo, com que método". (FOUCAULT, 2013, p. 408). A arte de governar deverá responder, primeiramente, à questão de como gerir indivíduos, bens e/ou riquezas no interior de uma família. Deverá introduzir a economia ao nível da gestão de um Estado, permitindo uma forma de vigilância, de controle, tão atenta em relação aos habitantes, às riquezas, aos comportamentos individuais e coletivos, quanto à de um pai de família. A arte de governar, que é a arte de exercer o poder segundo o modelo da economia (FOUCAULT, 2013, p. 414), somente foi possível com seu desbloqueio e a emergência do problema da população; com a instrumentalização da família comparativamente à população, que aparecerá como objetivo, finalidade, do governo.

Ao mencionar o texto de La Perrière, Foucault afirma que "o governo é uma correta 
disposição das coisas de que se assume o encargo, para conduzi-las a um fim conveniente" (FOUCAULT, 2013, p.416). Governam-se coisas e não territórios, tendo como alvo principal a população. Segundo o autor, seria esta a segunda característica da arte de governar.

Por fim, ainda trabalhando com o texto de La Perrière, Foucault afirma que o bom governante deve ter paciência, soberania e diligência. À força e à cólera se contrapõem a paciência, a sabedoria, que se traduz no conhecimento das coisas, dos objetivos que se deve atingir e da disposição para atingi-los, e a diligência, que faz com que o governante só deva governar na medida em que considere e aja como se estivesse ao serviço dos governados (FOUCAULT, 2013, p. 418). Ao traçar as características de um bom governante, cuja caracterização difere essencialmente da "Do Príncipe", de Maquiavel, Foucault se prepara para trabalhar o conceito de governamentalidade.

Em 1978, em um dos seus cursos proferidos no Collège de France, Michel Foucault (2003) proferiu a aula: "A governamentalidade". Nesta oportunidade, apresentou três pontos sobre o que ele denomina governamentalidade. Primeiramente, ela seria o

conjunto constituído pelas instituições, procedimentos, análises e reflexões, cálculos e táticas que permitem exercer essa forma bem específica, bem complexa, de poder, que tem como alvo principal a população, como forma mais importante de saber, a economia política, como instrumento técnico essencial, os dispositivos de segurança.

Em segundo lugar,

por "governamentalidade", seria a tendência que não cessou de conduzir, em direção à preeminência desse tipo de saber que se pode chamar de "governo" sobre todos os outros: soberania, disciplina. Isto, por um lado, levou ao desenvolvimento de toda uma série de aparelhos específicos de governo e, por outro, ao desenvolvimento de toda uma série de saberes.

Por fim,

por "governamentalidade", acho que se deveria entender o processo, ou melhor, o resultado tomado nos séculos XV e XVI pelo qual o Estado administrativo, encontrou-se, pouco a pouco, governamentalizado (FOUCAULT, 2003, p. 303).

Em outra oportunidade, Foucault apresenta novamente a ideia de governamentalidade, focando sua finalidade: gestão de indivíduos e população. Governar significa, então, criar instrumentos que possibilitem a submissão de sujeitos e populações às verdades e às tecnologias. $\mathrm{O}$ aspecto mais próprio do governo, entretanto, é sua relação específica com o poder. Para Foucault, o exercício do poder consiste em conduzir condutas e ordenar probabilidades. Governar é estruturar o eventual campo de ação dos outros, o modo de relação próprio do poder - que deve ser buscado ao lado do governo. As relações de governo são progressivamente governamentalizadas, racionalizadas, em busca de uma nova racionalidade empregada para atingir um fim. A estratégia se define pela escolha das soluções vencedoras (FOUCAULT, 1995). Ao privilegiar o enfoque do poder como estratégia, Foucault resiste a uma substancialização do poder. O poder aparece assim como da ordem do governo e não da ordem do enfrentamento entre adversários. "Governar, neste sentido, é estruturar o eventual campo de ação dos outros" - modos de ação destinados a agir sobre as possibilidades de ação dos outros indivíduos. (FOUCAULT, apud DREYFUS e RABINOW, 1995).

A reflexão sobre a natureza daquilo que é governado é o que torna a arte de governar racional. Governam-se coisas. Esta arte de governar implica um saber, que não é meramente uma prudência ou uma justiça, mas sim uma ciência de governo, um conhecimento sobre as forças do Estado e sua capacidade de desenvolvê-la, a fim de manter justamente o poder. O conhecimento passa a ser um elemento estratégico para o desenvolvimento da ratio do Estado moderno. Sem ciência, sem conhecimento, sem informação, não há governamentalidade.

A razão do Estado encontrará apoio em diversas instituições. É preciso dar à palavra "governo" a significação ampla que tinha no século XVI. Analisando a literatura antimaquiavélica do século XVI, Foucault apresenta a acepção desta palavra: 
Essas coisas das quais o governo deve encarregar-se são os homens, mas em suas relações, seus laços, seus emaranharamentos com essas coisas que são as riquezas, os recursos, as substâncias, o território, com certeza, em suas fronteiras, com suas qualidades, seu clima, sua aridez, sua fertilidade: são os homens em suas relações com essas outras coisas que são os costumes, os hábitos, as maneiras de fazer ou de pensar e, enfim, são os homens em sua relação com outras coisas ainda, que podem ser os acidentes ou as desgraças, como a fome, epidemia, a morte. (FOUCAULT, 2013, p.415).

Analisada desta forma, vê-se com clareza que a violência, a criminalidade, a gestão das mortandades - enquanto busca do "biopoder" por aumentar a vida - são situações das quais o governo deve se encarregar. A razão governamental moderna não compreende o fortalecimento da soberania para a manutenção do território, e sim o fortalecimento do governo para e através da gestão da população. A preocupação com a delinquência, com a prevenção de condutas individuais e coletivas, enquanto fenômenos populacionais, passa a ser considerada como fundamental para o governo. Os dispositivos de segurança visam manter a criminalidade dentro de limites entendidos como social e economicamente aceitáveis, em torno de uma média considerada aceitável para o funcionamento social. Dentro de uma lógica, o gerenciamento da informação aparece como uma estratégia orientada para a escolha de soluções vencedoras no campo da segurança pública.

Reconhecer a criminalidade e a violência enquanto questões relacionadas à como gerir e conduzir a população nos permite, como dito, situá-las como uma questão de governo. Desta forma, a governamentalidade moderna deve, através da criação de dispositivos de segurança, se ocupar com o controle da delinquência.

A construção teórica busca elementos para percebermos o discurso sobre um novo paradigma de segurança pública - pautado inclusive na gestão municipal - como uma reorganização do exercício do poder e não simplesmente uma ruptura com os discursos anteriores. Esta transformação visa elaborar procedimentos mais ajustados à gestão da delinquência -, levando em consideração as potencialidades do poder muni- cipal para reorganizar essa área de atuação. Segundo Foucault, "o exercício do poder não é um fato bruto, um dado institucional, nem uma estrutura que se mantém ou se quebra: ele se elabora, se transforma, se organiza, se dota de procedimentos mais ou menos ajustados" (FOUCAULT, apud DREYFUS e RABINOW, 1995, p.17), que visam, como dito, à escolha de estratégias vencedoras que objetivam a manutenção do poder. Afinal,

o poder é um conjunto de mecanismos e de procedimentos que têm como papel ou função e tema manter - mesmo que não consigam - justamente o poder. É o conjunto de procedimentos, e é assim e somente assim que se poderia entender que a análise dos mecanismos de poder dá início a algo como a teoria de poder. (FOUCAULT, 2008, p.04).

Finalmente, entender os dispositivos de segurança de uma determinada sociedade é buscar uma análise que recairá sobre o próprio poder, ou melhor, sobre as relações de poder. É atrativo o pensamento de que a inclusão do município na segurança pública é decorrência de uma ruptura com as estruturas anteriores - centralizadoras e focadas na ideia de Segurança do Estado -, permitindo uma gestão da segurança pública mais descentralizada, participativa e focada nas especificidades das cidades, enquanto locus da manifestação da violência. No entanto, buscamos elementos conceituais e teóricos para perceber que o discurso da importância do município na segurança pública faz parte de um complexo mecanismo - dispositivo - que busca a manutenção e fortalecimento do poder, através da manutenção da capacidade de governo. A garantia das condições de governo, inclusive com o reforço na relação de confiança entre governantes e governados, é essencial para propagação de um saber/poder que tem por finalidade conduzir/ governar a população. Assim, é essencial perceber que nosso problema foi construído através da percepção de que uma nova forma de gestão da segurança pública decorreu do questionamento do papel tradicional do Estado, em virtude do aumento da violência. A dimensão política do problema da violência estaria relacionada à baixa legitimação da autoridade política do Estado (CARVALHO, 1995). 
Predominante, nos últimos anos, a responsabilidade da gestão da segurança pública esteve sob a égide das instâncias federal e estadual. Esta configuração passou a ser questionada em um momento em que se vivia um distanciamento indesejável entre o problema da segurança pública e a capacidade ou autoridade institucional em resolvê-lo. Nesse sentido, tem se tornado bastante comum ressaltar a importância do papel dos municípios, ao lado dos governos estaduais e do federal, no que se refere ao combate à criminalidade e à violência. (PEREIRA, TONELLI e OLIVEIRA, 2013, p.09).

Nesta abordagem, as alterações legislativas - ao permitirem e fomentarem a atuação no município na segurança pública - devem ser apreendidas não como uma continuidade, uma evolução, e sim o produto, ainda inacabado, de uma série de lutas, interesses e enfrentamentos ocorridos em um campo de conhecimento. Dessa forma, todos os discursos, mesmo que se apresentem como formas de resistência ao discurso dominante, desejam se tornar dominantes. Não há discursividade que não manifeste relações e interesses de poder.

Segundo Foucault (2005, p. 28), os mecanismos de poder ou o "como do poder" podem ser apreendidos entre dois pontos de referência ou dois limites: de um lado as regras do Direito atuam delimitando formalmente o poder; de outro lado, elas seriam os efeitos de verdade que este poder produz, que este poder conduz e que, por sua vez, reconduzem esse poder. Contrapondo-se à percepção iluminista de que o Direito atua como limitador do arbítrio do poder soberano, as regras jurídicas passam a ser instrumentos que conduzem à verdade e, consequentemente, ao poder. (FOUCAULT, 2005, p. 28). O triângulo "poder, verdade e direito" é essencial para analisar a participação do município na segurança pública, de modo a utilizar o dispositivo como função metodológica.

Segundo Foucault, a análise de um dispositivo leva em consideração os elementos que intervieram em uma racionalidade, em uma organização. Enquanto ferramenta metodológica, o dispositivo apresenta três pontos a serem demarcados. Em primeiro lugar, um conjunto decididamente heterogêneo que engloba discursos, instituições, organizações arquitetônicas, decisões regulamentares, leis, medidas administrativas, enunciados científicos, proposições filosóficas, morais, filantrópicas. Em suma, o dito e o não dito são elementos do dispositivo. O dispositivo é a rede que se pode estabelecer entre esses elementos. (FOUCAULT, 2013, p.364).

Ao longo de nossa pesquisa, tentamos abordar como ocorreu, no âmbito legal normativo, o processo de reconhecimento da importância da participação do município nos debates da segurança pública, quais foram os principais discursos apresentados para justificar a inserção de tal ente federativo neste campo de atuação, bem como as questões que tangenciam o problema. Buscamos trazer elementos para a compreensão de como o município vem integrando, paulatinamente, esse complexo dispositivo da segurança - reconhecendo, desde já, que estamos diante de um processo em construção.

Em segundo lugar,

gostaria de demarcar a natureza da relação que pode existir entre esses elementos heterogêneos. Sendo assim, tal discurso pode aparecer como programa de uma instituição ou, ao contrário, como elemento que permite justificar e mascarar uma prática que permanece muda; pode ainda funcionar como reinterpretação desta prática, dando-lhe acesso a um novo campo de racionalidade. Em suma, entre estes elementos, discursivos ou não, existe um tipo de jogo, ou seja, mudanças de posição, modificações de funções, que também podem ser muito diferentes. (FOUCAULT, 2013, p. 364).

Em terceiro lugar, "entendo dispositivo como um tipo de formação que, em determinado momento histórico, teve como função principal responder a uma urgência. $\mathrm{O}$ dispositivo tem, portanto, uma função estratégica dominante". (FOUCAULT, 2013, p. 364/365).

A busca pela inserção do município no campo da segurança pública pode ser entendida pelo que Foucault chama de "preenchimento estratégico do dispositivo" (FOUCAULT, 2013, p 
366). A perda da força do Estado pode ser percebida como um efeito do processo de gestão da delinquência. Exige uma rearticulação, um reajuste dos elementos heterogêneos que surgem dispersamente. Um eterno processo de preenchimento estratégico. A repressão, enquanto forma de gerir a delinquência, encontra seu ápice na fase ditatorial. Os abusos cometidos reforçam o discurso de resistência, construindo um novo paradigma de segurança pública. Dentro dele, torna-se necessária uma nova estratégia, que de certa forma ocupe o espaço vazio ou transforme o negativo em positivo: o discurso da ineficácia das políticas tradicionais de segurança pública cria uma nova racionalidade, a qual, pautada em outro discurso, visa a mesma finalidade: manter a governamentalidade e gerir as ilegalidades através da delinquência.

Obviamente, tal alteração estratégica que pode ser vista como uma intervenção racional e organizada em uma determinada direção - teve de ser orientada por outros saberes e discursos. Um aspecto que ganha destaque, como já abordado, é o da percepção da cidade como locus do exercício da cidadania. Por isto, o município deve ter ações que permitam a real utilização do espaço público, visto que a criminalidade pode ser percebida também como um problema de urbanização.

A capacidade de o Município articular a sociedade civil - que se apresenta como um elemento estruturante dentro de uma lógica de segurança pública cidadã - também reforça os argumentos para justificar a participação deste ente na gestão da violência urbana. Vários mecanismos, cuja finalidade é reforçar a participação da sociedade nas políticas de segurança, são apontados como essenciais, e o discurso da comunidade e da cidadania pode ser percebido como importante para a legitimidade das decisões neste campo de atuação. Apesar de tal discurso ser decorrência de um processo de fortalecimento dos direitos individuais e sociais, não podemos desconsiderar a possibilidade de tais mecanismos serem apropriados pelas instituições, a fim de validarem decisões impostas. A não instrumentalização dos mecanismos de participação popular estaria relacionada à capacidade emancipatória dos indivíduos. A descrença foucaultina no discurso racional modernista -- notadamente em virtude dos mecanismos de subjetivação da sociedade moderna - tornam esse ponto relevante quando da análise de um caso concreto. Concluindo: devemos considerar - sem generalizar - a possibilidade de o discurso da comunidade e da cidadania, baseado no comportamento racional dos governados, ser orientado no sentido de conduzir condutas e induzir práticas que trabalhem a gestão política dos homens/cidadãos para o aumento da própria força do Estado.

Por fim, o envolvimento efetivo do chefe do executivo municipal apresenta-se como indispensável para uma nova racionalidade na gestão da segurança pública - racionalidade esta que busca a manutenção e fortalecimento do poder do Estado. Governam-se coisas para conduzi-las a um fim conveniente. Pela proximidade, o gestor municipal é chamado a atuar diretamente nas demandas relacionadas à segurança. Seria a reapropriação do poder pastoral pela arte de governar. O pastor, para bem conduzir seu rebanho, deve conhecê-lo. Esperase do prefeito municipal conhecimento sobre os problemas locais, da população, bem como sobre os objetivos que pretende atingir, já que a produção e gerenciamento do conhecimento podem ser vistas como importantes estratégias a seu serviço. A questão apresentada busca solucionar a problemática geral de como ser um bom governante.

\section{CONSIDERAÇÕES FINAIS}

Apesar da sedutora ideia de que a concepção de Segurança Cidadã e, consequentemente, de descentralização das politicas de segurança pública, a alcançar, inclusive, os municípios, seria uma ruptura com um modelo centralizador e repressivo, a construção teórica apresentou elementos para a percepção de tal discurso como uma reorganização do exercício do poder e não simplesmente uma ruptura com os discursos anteriores. Impulsionado pelo aumento da sensação de insegurança e altos índices de criminalidade nas últimas décadas, tornou-se necessário um rearranjo dos elementos heterogêneos capazes de transformar o "negativo" em "positivo". Nesse sentido, os excessos imputáveis às políticas repressivas durante o período ditatorial, dão espaço ao discurso preventivo. Dentro do processo de preenchimento estratégico, cria-se uma nova racionalidade voltada sempre a mesma finalida- 
de: manutenção das condições de governo. Neste sentido, a percepção Foucaultiana de que o exercício do poder se transforma, organiza, elabora. (FOUCAULT, apud DREYFUS e RABINOW, 1995, p.17).

A segurança pública entra na agenda municipal dentro de um contexto de busca de novos discursos, novas estratégias, e em que a violência urbana é identificada como uma má gestão dos problemas locais. A garantia das condições de governo, inclusive com o reforço na relação de confiança entre governantes e governados, é essencial para propagação de um saber/poder que tem por finalidade conduzir/governar a população. A dimensão política do problema da violência estaria relacionada à baixa legitimação da autoridade política do Estado (CARVALHO, 1995).

Através da construção foucaultiana, percebe-se que a gestão da população através de questões como violência, criminalidade, são situações das quais o governo deve se encarregar. Os dispositivos de segurança são necessários para manter a delinquência dentro de limites entendidos como aceitáveis para o funcionamento social. Trata-se de uma estratégia cuja finalidade é a escolha das melhores soluções, as soluções vencedoras, no complexo campo da segurança pública. Desta forma, reconhecer a criminalidade como uma questão de como geria, conduzir a população, nos permite situá-la como uma questão de governo.

Como dito, a finalidade principal deste artigo foi trazer elementos para compreender a segurança pública como um problema de governamentalidade. A utilização de tal instrumental permitiu construir uma percepção crítica da atuação do município nesta área. "Crítica", não quer dizer que seja ruim ou desnecessária, muito pelo contrário. A reformulação no campo do controle do crime e, consequentemente, da segurança pública, é indispensável para atender às demandas da sociedade contemporânea. No entanto, a sinalização para a inexistência de rupturas com o paradigma anterior, evidencia que todas as alterações, por mais necessárias ou inadiáveis que sejam, reconduzem à mesma lógica de manutenção do poder. Como dito, Foucault reconhece que as relações de poder são essenciais para a manutenção da vida em sociedade. Romper com a visão fatalista de ser o poder algo essencialmente ruim pode ser o caminho para apreensão de nossa proposta que busca, para além de trazer novas percepções para o campo, indicar que ele se encontra em um contínuo processo de construção e remodelagem.

\section{REFERÊNCIAS BIBLIOGRÁFICAS}

ADORNO, S.; LAMIM, C. Medo, violência e insegurança.In: LIMA, R.S.; PAULA, L. (Orgs.). Segurança Pública e violência: O Estado está cumprindo seu papel? São Paulo: Contexto. $1^{\text {a }}$ Ed, 2008, p. 150-171.

ALVES, M. C. Gestão local e políticas públicas: os desafios do campo da segurança. Disponível em: <http://www.forumseguranca.org.br/storage/ download//anuario_ii_-_gestao_local_e_ politicas_publicas_-_os_desafios_do_campo_ da_seguranca1.pdf $>$. Acesso em: 18.set.2014.

BARREIRA, César. Em nome da lei e da ordem: a propósito da política de segurança pública. São Paulo Perspec., São Paulo, v. 18, n. 1, p. 77-86, Mar. 2004 . Disponível em: <http://www.scielo. br/scielo.php? script $=$ sci_arttext $\&$ pid $=$ S0102$88392004000100011 \& \operatorname{lng}=\mathrm{en} \& \mathrm{nr} \mathrm{m}=\mathrm{iso}>$. Acesso em: 24 Jun. 2015.

BRASIL. Lei $\mathrm{n}^{\circ} 11530$, de 24 de outubro de 2007. Institui o Programa Nacional de Segurança Pública com Cidadania - PRONASCI e dá outras providências. Brasília, DF. Disponível em: http:// www.planalto.gov.br. Acesso em 21.mar.2015.

CANDIOTTO, C. Foucault e a crítica da verdade. Série estudos foucaultianos. $2^{\mathrm{a}}$ ed. Belo Horizonte: Autentica Editora; Curitiba: Champagnat, 2013.

CARVALHO, M.A.R de. A cidade escassa e violência urbana.Instituto Universitário de Pesquisa do Rio de Janeiro. Sociedade Brasileira de Instrução. n. 91.Série Estudos. Agosto de 1995. Disponível em: <http://www.cis.pucrio.br/cedes/ banco\%20artigos/Direito\%20e\%20Cidade/ maria\%20alice.pdf $>$. Acesso em: 12.06.2014.

CASTELLS. M; BORJA. J. As cidades como atores políticos. Tradução Omar Ribeiro Thomaz. Novos Estudos. v.45, p. 152-166, Jun.1996.

CHAVES, J. O Problema do Direito em Michel Foucault: entre imagens jurídicas e a proposta de 
um direito novo. Editora Juruá, Curitiba, 2010.

Do Poder Pastoral à Governamentalidade. Disponível em: <http://www.maxwell.vrac. puc-rio.br/9999/9999_5.PDF $>$. Acesso em: 25.abr.2015.

FOUCAULT, M. Segurança, Território, População. Martins Fontes. São Paulo, 2008. (Aula: 1 de fevereiro).

FOUCAULT, M. Microfísica do Poder. Graal. Organização, introdução e revisão técnica Roberto Machado. 26ª ed. São Paulo, 2013.

.Estratégia, Poder - Saber. Coleção Ditos e escritos IV. Organizador Manoel Barros da Motta. Forense Universitária. Tradução Vera Lúcia Avellar Ribeiro. 2003.

.Vigiar e Punir: Nascimento da prisão. $38^{\circ}$ ed. Editora Vozes. Petrópolis 2010. Trad. Raquel Ramalhete.

. Sujeito e Poder. In: Dreyfus, Hubert L; Rabinow, Paul. Tradução Vera Porto Carrero. Uma trajetória Filosófica: Para além do estruturalismo e da hermenêutica. Rio de Janeiro: Forense Universitária, 1995.

. Em defesa da sociedade. Curso no Collège de France (1975-1976). Martins Fontes, 2005. Tradução Maria Ernantina Galvão.

FRAGA, P.C.P. Governamentalidade e poder no pensamento de Foucault. Fragmentos de Cultura, Goiânia, v.12 (especial), p.69-89, mar.2002.

FREIRE, M. D. Paradigmas de segurança no Brasil: da ditadura aos nossos dias. Revista Brasileira de Segurança Pública, São Paulo, Ano.3, 5a Ed., p.100-114, ago./set.2009.

FREY, K.; CZAJKOWSKI, S. O município e a segurança pública: o potencial da governança democrática urbana. RAP, Rio de Janeiro. 39(2), p. 297-325, Mar/Abr. 2005.

GARLAND, D. A cultura do controle. Crime e ordem social na sociedade contemporânea. Tradução André Nascimento. Rio de Janeiro: Revan, 2008.
GUINDANI, M; SOARES, L.E. Porto Alegre: Relato de uma Experiência. In: SENTO-SÉ, J.T. Prevenção da Violência: O Papel das Cidades. Rio de Janeiro: Editora Civilização Brasileira, 2005, p. 283-332.

KRUCHIN, M. K. Análise da introdução de um novo paradigma em segurança pública no Brasil. Revista Brasileira de Segurança Pública, São Paulo, v.7, n.1, p.40-56, fev/mar. 2013.

MESQUITA, N. P. Segurança, justiça e direitos humanos no Brasil. In: LIMA, R. S.; PAULA, L. (Orgs.). Segurança Pública e violência: O Estado está cumprindo seu papel? São Paulo: Contexto. $1^{\text {a }} \mathrm{Ed}, 2008$, p.53-64.

MIKI, R. Participação do município na segurança pública. Disponível em: <http://www. forumseguranca.org.br/storage/download// anuario_ii_-_participacao_do_municipio_ na_seguranca_publical.pdf $>$. Acesso em: 05.dez.2014.

MIRAGLIA. P. Os Municípios e a segurança pública. In: LIMA,R.S.;PAULA, L. (Orgs.). Segurança Pública e violência: O Estado está cumprindo seu papel? São Paulo: Contexto. $1^{\text {a }}$ Ed, 2008, p.89-99.

RICCIO, V. O Município e a Segurança: O Sistema Legal como Instrumento da Gestão da Ordem Pública. 2012. Disponível em: http:// profmoraes.files.wordpress.com.

ROSE, N.; MILLER, P. Governing the presente. Cambridge: Polity Press. 2008.

SEGURANÇA E CIDADANIA. Memórias do Pronasci: depoimentos ao Cpdoc. In:FERREIRA,M.M; BRITTO,A (Orgs.). Rio de Janeiro: FGV. $1^{\text {a ed. }} 2010$.

SILVA, J.C. Manutenção da ordem pública e garantia dos direitos individuais: os desafios da polícia em sociedades democráticas. Revista Brasileira de Segurança Pública. São Paulo, ano 5, ed. 8, p.78-89, fev/mar. 2011.

SOARES, L.E. Segurança Municipal no Brasil. In: SENTO-SÉ, J.T. Prevenção da Violência: O Papel das Cidades. Rio de Janeiro: Editora Civilização 
Brasileira, 2005, p. 15-45.

SHORE,C.; WRIGHT, S. (eds). Anthropology of policy. Critical perspectives on governance and power. London and New York: Routledge, 1997, pp. 3-39.

WAISELFISZ, J.J. Mapa da violência 2013: Mortes matadas por arma de fogo. Centro Brasileiro de Estudos Latino-Americanos. Flacso-Brasil.

WAISELFISZ, J.J. Mapas da Violência 2014: Os Jovens do Brasil. Rio de Janeiro: FLACSO, 2014. Disponível em: <http://www.mapadaviolencia. org.br/pdf2014/Mapa2014_JovensBrasil_ Preliminar.pdf $>$. Acesso em: 18.abr.2015.

ZAVERUCHA, J. A Crescente Inserção das Forças Armadas na Segurança Pública. In: CRUZ, M.V.G.; BATITUCCI, E.C. Homicídios no Brasil. Rio de Janeiro: Editora FGV, 2007, p. 25-50. 